
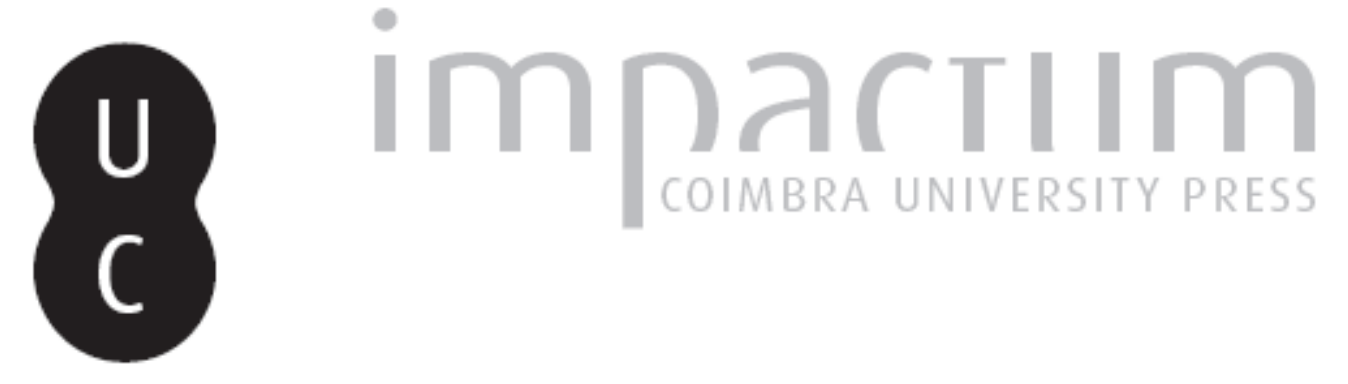

\title{
A valoração da prova pericial
}

Autor(es): $\quad$ Sousa, Luís Filipe Pires de

Publicado por: Imprensa da Universidade de Coimbra

URL persistente:

URI:http://hdl.handle.net/10316.2/43557

DOI:

DOI:https://doi.org/10.14195/1647-8630_27_1

Accessed : $\quad$ 26-Apr-2023 11:25:52

A navegação consulta e descarregamento dos títulos inseridos nas Bibliotecas Digitais UC Digitalis, UC Pombalina e UC Impactum, pressupõem a aceitação plena e sem reservas dos Termos e Condições de Uso destas Bibliotecas Digitais, disponíveis em https://digitalis.uc.pt/pt-pt/termos.

Conforme exposto nos referidos Termos e Condições de Uso, o descarregamento de títulos de acesso restrito requer uma licença válida de autorização devendo o utilizador aceder ao(s) documento(s) a partir de um endereço de IP da instituição detentora da supramencionada licença.

Ao utilizador é apenas permitido o descarregamento para uso pessoal, pelo que o emprego do(s) título(s) descarregado(s) para outro fim, designadamente comercial, carece de autorização do respetivo autor ou editor da obra.

Na medida em que todas as obras da UC Digitalis se encontram protegidas pelo Código do Direito de Autor e Direitos Conexos e demais legislação aplicável, toda a cópia, parcial ou total, deste documento, nos casos em que é legalmente admitida, deverá conter ou fazer-se acompanhar por este aviso.

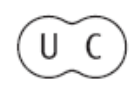


ISSN: 1645-0760

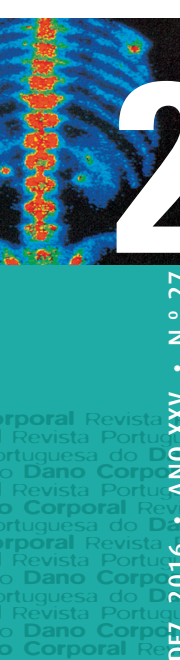

REVISTA PORTU/GUESA
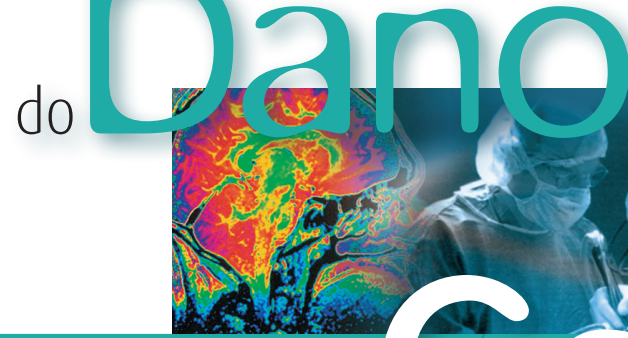

N

z.

希ort

Do

: inta Cortuguesa do Dano Corporal Revista Portuguesa do Dano Corporal Revista Portuguesa

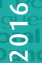

ầं।

Corporal Revista Portuguesa do Dano Corporal Revista Portuquesa do Dano Corporal

I Revista Portuguesa do Dano Cortuguesa do Dano Corporal Revista Portugues
Revista Pdrtuguesa do Dano Corporal

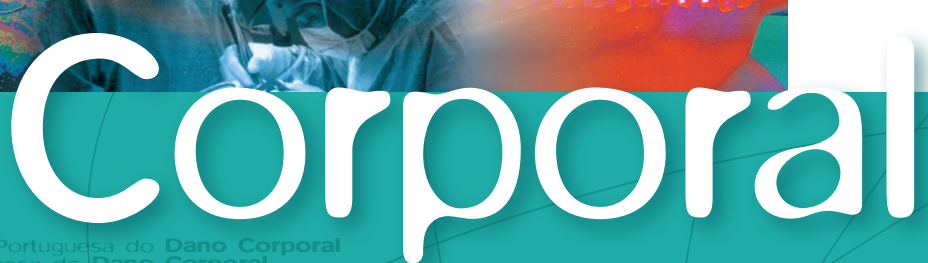

APADAC

ASSOCIAÇÃO PORTUGUESA

DE AVALIAÇÃO

DO DANO CORPORAL 


\title{
A valoração da prova pericial
}

\author{
Luís Filipe Pires de Sousa ${ }^{1}$
}

Resumo: A valoração da prova pericial.

Neste artigo analisamos a prova pericial em especial os standards que o julgador de facto deve seguir quanto avalia a prova pericial. Discutimos o papel do juiz e o papel do perito, defendendo que o juiz mantém a sua autonomia e que o perito não pode fazer as vezes de juiz.

Palavras-chave: Prova pericial; perito; teste Daubert.

Summary: The valuation of expert evidence.

In this article we analyze scientific evidence specially the standards that the trier of fact must follow when assessing scientific evidence. We discuss the role of the judge and the role of the expert witness, defending that the judge keeps his autonomy and the expert can't serve as judge.

Key-words: Scientific evidence; expert testimony; Daubert test.

"A questão da responsabilidade médica é largamente prejudicada pela invasão dos homens de direito."

LESSEPS LOURENÇO DOS REYS, "Responsabilidade civil dos médicos", in RFML, Série III, Vol. 5, Nº5, p. 312, citando ETCHEGOYEN, A Era dos Responsáveis, 1995, p. 133.

Partamos de uma situação típica e recorrente: numa perícia colegial, os peritos pronunciam-se de forma díspar sobre a resposta a determinada questão que integra os Temas da Prova.

1 Juiz Desembargador 
Como decide o juiz? Na maioria das situações, o juiz utiliza como critério de decisão o argumento da imparcialidade do perito do tribunal para dar prevalência ao laudo deste, descartando o laudo dos peritos das partes.

Em psicologia cognitiva, esta atuação do juiz integra um viés de grupo (“ingroup bias"), o qual consiste numa técnica cognitiva segundo a qual se valora, de forma injustificadamente homogénea, as atitudes, os atos e opiniões das pessoas que pertencem ao mesmo grupo, pela simples razão de pertencerem a esse grupo. Trata-se de uma forma de identificação social em que o sujeito dá um tratamento preferente aos membros do grupo a que pertence.

Contudo, este ratio decidendi assenta ele próprio numa presunção, qual seja a de que o perito do tribunal é mais isento do que os peritos das partes. Presunção naturalmente ilidível e cujo valor epistemológico é discutível.

A valoração da prova pericial tem de assentar em critérios mais profundos, científicos e objetiváveis, de que curaremos a seguir.

Como sabemos, no processo civil a prova pericial é apreciada livremente pelo tribunal (Artigo $389^{\circ}$ do Código Civil).

A apreciação da prova pericial abrange:

(i) A profissionalidade do perito;

(ii) A análise dos requisitos internos do laudo pericial e

(iii) A observância, na elaboração do mesmo, de parâmetros científicos de qualidade bem como o uso de resultados estatísticos.

No que tange à profissionalidade do perito, é curial começar por impor ao perito que apresente o seu curriculum na parte em que este possa evidenciar especial qualificação para a realização da perícia. Os conhecimentos, habilidades e experiência profissional do perito constituem fatores diferenciadores do mesmo. Releva, sobretudo, saber se já efetuou anteriormente perícias do mesmo teor. Relevará mais a trajetória científica do perito do que propriamente o cargo que ocupe.

Cabe ao juiz, em segunda linha, verificar se o laudo é inteligível e não apresenta contradições, ou seja, verificar se o mesmo é coerente. O perito deve ter presente que elabora o laudo para não especialistas pelo que deve fazer um esforço suplementar de expor as suas conclusões de forma clara, precisa e congruente, sem deixar pontas soltas. 
Quanto à observância de parâmetros científicos, acompanhando de perto Nieva Fenoll ${ }^{2}$, o juiz deve analisar se o laudo cumpre os seguintes requisitos:

2 La Valoración de la Prueba, Marcial Pons, Madrid, 2010, pp. 294-298.

A proposta de Nieva Fenoll é tributária e entronca, em grande parte, na jurisprudência gerada nos Estados Unidos a partir do caso Daubert vs. Merrell Dow Pharmaceuticals, Inc., de 1993. Nesse processo discutia-se se um fármaco denominado Bendectin poderia ter provocado lesões num recém-nascido. 0 juiz Blackmun ditou um tratado sintético de epistemologia com o propósito de elencar os critérios a que o juiz deve ater-se para admitir ou excluir os meios de prova científicos apresentados pelas partes. São quatro os critérios propostos:

a) a controlabilidade ou falsificabilidade da teoria científica ou da técnica em que se fundamenta a prova;

b) a percentagem de erro conhecido ou potencial, assim como o cumprimento dos estandares correspondentes à técnica empregue;

c) a publicação da teoria ou técnica em questão em revistas submetidas ao controlo de outros peritos;

d) a existência de um consenso geral da comunidade científica interessada.

A preocupação subjacente a estes critérios é a de deixar fora do âmbito probatório conhecimentos que se apresentam como científicos mas que não correspondem efetivamente a paradigmas partilhados de validade científica - cf. Michele Taruffo, La Prueba, Marcial Pons, 2008, pp. 283-284. Na apreciação de Paulo Dá Mesquita, A Prova do Crime e o que se Disse Antes do Julgamento. Estudo Sobre a Prova no Processo Penal Português, À Luz do Sistema Norte-Americano, Coimbra Editora, 2011, p. 372, Nota 277, segundo o Acórdão Daubert, "a ciência é entendida numa perspetiva de busca da verdade e entendimento cósmico baseado na persuasão, primariamente, numa particular comunidade de pares." $\mathrm{Na}$ expressão de Champod e Vuille, ScientificEvidence in Europe. Admissibility, Appraisal and Equilaty of Arms, European Committee on Crime Problems, 2010, p. 26, apudGascónAbellán, "PruebaCientífica. Un Mapa de Retos", in CarmenVásquez (ed.), Estándares de Prueba y Prueba Científica, Marcial Pons, Madrid, 2013, p. 193, a sentença Daubert "insiste de maneira implícita sobre o ceticismo que o juiz deve manter em relação ao perito, o qual deixa de ser considerado como o membro de uma elite com autoridade e passa a ser um agente social comparável a qualquer outro, eventualmente submetido a pressões de ordem política e económica que podem alterar o seu relatório."

As Federal Rules of Evidence na Rule 702, sob a epígrafe "Testimony by Expert Witnesses", acolhendo em grande parte a doutrina Daubert, dispõem que:

"A witness who is qualified as an expert by knowledge, skill, experience, training, or education may testify in the form of an opinion or otherwise if:

(a) The expert's scientific, technical, or other specialized knowledge will help the trier of fact to understand the evidence or to determine a fact in issue;

(b) The testimony is based on sufficient facts or data;

(c) The testimony is the product of reliable principles and methods; and

(d) The expert has reliable applied the principles and methods to the facts of the case."

Por sua vez, no Reino Unido a Law Commission, The Admissibility of Expert Evidence in Criminal Proceedings in England and Wales. A New Approach to the Determination of Evidentiary Reliability, http:// lawcommission.justice.gov.uk/docs/cp190_Expert_Evidence_Consultation.pdf, pronuncia-se assim:

"We provisionally propose a list of guidelines along the following lines for scientific (or purportedly scientific) expert evidence:

(1) In determining whether scientific (or purportedly scientific) expert evidence is sufficiently reliable to be admitted, the court shall consider the following factors and any other factors considered to be relevant:

(a) whether the principles, techniques and assumptions relied on have been properly tested, and, if so, the extent to which the results of those tests demonstrate that they are sound; 


\section{1- As técnicas e teorias científicas utilizadas para obter dados e conclu-} sões foram já utilizadas previamente, são relevantes e estão geralmente aceites pela comunidade científica internacional. A indagação sobre a observância deste requisito pode alcançar-se mediante:

- A menção das publicações científicas ou manuais onde estão expostas essas técnicas e teorias que foram utilizadas;

- Subsidiariamente, deverá ser explicitada a técnica utilizada e se a mesma é de uso comum na práxis científica ou profissional;

- A descrição pelo perito do procedimento de análise que realizou bem como os instrumentos de que se socorreu na sua tarefa. Ou seja, é necessário explicar o iter técnico que o conduziu às suas conclusões. Só assim de pode confrontar a metodologia do perito com a dos demais. Acresce que a não explicitação da metodologia faz com que os resultados fiquem a pairar no vazio, sucumbido arrimo ao juiz para apreciar criticamente o laudo.

(b) the margin of error associated with the application of, and conclusions drawn from, the principles, techniques and assumptions;

(c) whether there is a body of specialized literature relating to the field;

(d) the extent to which the principles, techniques and assumptions have been considered by other scientists - for example in peer-reviewed publications - and, if so, the extent to which they are regarded as sound in the scientific community;

(e) the expert witness's relevant qualifications, experience and publications and his or her standing in the scientific community;

(f) the scientific validity of opposing views (if any) and the relevant qualifications and experience and professional standing in the scientific community of the scientists who hold those views; and

(g) whether there is evidence to suggest that the expert witness has failed to act in accordance with his or her overriding duty of impartiality."

Michele Taruffo, "La Aplicación de Estándares Científicos a las Ciencias Sociales Forenses", in Carmen Vásquez (ed.), Estándares de Prueba y Prueba Científica, Marcial Pons, Madrid, 2013, pp. 208-209, enfatiza que os critérios adotados no caso Daubert foram confecionados para as ciências duras ou da explicação (v.g., física, química, engenharia), não se estando a pensar propriamente nas ciências sociais ou da compreensão (v.g., psicologia, sociologia). Nas palavras de Taruffo, «(...) há uma clara diferença entre os paradigmas de ambos os grupos de ciências: as ciências humanas, em particular, não usam o paradigma nomológico hempeliano, que é próprio das ciências naturais. Dado que os standards Daubert, como qualquer outro standard aplicável às ciências duras, não podem ser aplicados a ciências com paradigmas fundamentalmente diferentes, estamos perante o problema de estabelecer que standards de validade científica, se é que há algum, podem ser aplicados às ciências sociais. Um importante problema adicional é que essas ciências não formam um conjunto homogéneo: cada uma delas tem o seu próprio paradigma (ou paradigmas). Dentro de semelhante variedade, alguns critérios de validade científica devem definir-se simplesmente tomando em consideração as caraterísticas específicas de cada ciência.» Entre a escassa jurisprudência nacional que refere a doutrina Daubert, veja-se o Acórdão do Tribunal da Relação de Évora de 21.10.2010, Gomes de Sousa, 281/04. 
2- As técnicas utilizadas foram aplicadas segundo os padrões e normas de qualidade vigentes. Apela-se aqui às normas internas de cada profissão em que se incluem normas deontológicas e manuais de boas práticas.

3- O laudo contém informação sobre o nível de erro e sobre a graduação de variabilidade e incerteza dos dados obtidos através da técnica ou teoria científica utilizadas. O que se visa aqui é que o laudo contenha informação estatística contrastável sobre o acerto dos seus resultados. Esse contraste pode ser alcançado pelo recurso a publicações científicas sobre a matéria. Por exemplo, numa singela avaliação de um imóvel, o perito tem de investigar e demonstrar preços de vendas de imóveis similares. Em matérias de índole mais científica, pode mesmo chegar-se à conclusão que inexiste investigação alargada sobre o assunto, eventualidade em que a prova pericial não terá a mesma força.

4- O laudo deve sustentar-se em suficientes factos e dados, não devendo o perito bastar-se com meras amostras ou elementos colhidos de forma incompleta ou precipitada.

Este conjunto de critérios objetivos permite ao juiz, na ausência de conhecimentos científicos equiparáveis ao do perito, formular um juízo sobre o mérito intrínseco e grau de convencimento a atribuir ao laudo pericial.

No caso da coexistência de relatórios periciais contraditórios, o juiz deve recorrer aos critérios ora enunciados para graduar o valor dos laudos e escolher o que será mais convincente. Com efeito, o juiz não poderá formular essa graduação com base em conhecimentos científicos. Deverá proceder à análise de cada um dos laudos de acordo com os critérios objetivos enunciados de modo que o laudo prevalecente será o que obtiver melhor resultado nessa análise individual, feito critério a critério. Se essa análise não conduzir a resultados claros no sentido da prevalência de um laudo sobre os demais, resta ao juiz aplicar as regras de decisão decorrentes do ónus da prova (no processo civil) ou da presunção da inocência (no processo penal). ${ }^{3}$

Sintetizando o que fica dito com recurso a ideias-chave mais sucintas, diremos que no que tange aos critérios de valoração da prova pericial, quer no caso de perícia uniforme quer no caso de perícias contraditórias, os fatores que deverão ser tidos em conta para apreciar a força de convicção

3 Consoante veremos infra, o regime de apreciação da prova pericial no processo penal contém peculiaridades no que tange à admissibilidade do juiz dissidir do laudo pericial. 
dos laudos e a escolha por um em detrimento de outros serão nomeadamente os seguintes:

- A qualificação do perito e a maior especialização e prática na matéria objeto da perícia;

- O método de proceder utilizado mediante a descrição das operações levadas a cabo pelo perito pois na perícia tão importante como a conclusão é o que caminho que se seguiu para chegar a esta;

- O contato direto e a imediação temporal no exame que constitui a fonte de prova;

- A disponibilidade de meios técnicos e equipamentos de análise, assim como o procedimento utilizado pelo perito; ou a justificação de o perito ter optado por um dos procedimentos possíveis em detrimento de outros;

- A coerência, motivação e racionalidade das conclusões. A prova pericial mais apropriada é aquela que se apresenta melhor fundamentada e veicula maiores razões de ciência e objetividade ${ }^{4}$.

Face ao que fica exposto, o critério da imparcialidade do perito do tribunal deverá ser relativizado, não podendo partir-se do pressuposto que o perito da parte é menos profissional ou parcial. O laudo do perito da parte pode ser imparcial na medida em que assista razão à parte. Os critérios decisivos são os enunciados e não qualquer apriorismo sobre as relações dos peritos com as partes. Mais do que a imparcialidade do perito releva a qualidade da perícia porquanto um perito, mesmo imparcial, pode cometer erros, ter convicções erradas, usar técnicas inadequadas, etc. ${ }^{5}$

O juiz não é um recetor passivo da opinião do perito, assistindo-lhe o poder/dever de valorar autonomamente tal prova. Neste âmbito, é conhecido o brocardo iudex peritus peritorum cujo sentido específico merece densificação. A análise crítica que o juiz faz do laudo servirá para adquirir um convencimento sobre o seu resultado, assumindo ou não as conclusões do laudo, das quais extrairá as máximas da experiência necessárias para a apreciação dos factos relevantes. O juiz valora as máximas de experiência especializadas trazidas pelo perito aplicando máximas de experiência comuns para o que não são necessários conhecimentos especializados mas apenas capacidade crítica de entendimento e apreciação.

4 Maria Martínez Urrea, "La valoración de dictámes periciales contraditórios", in Aspetos problemáticos en la valoración de la prueba civil, Bosch Procesal, 2008, p. 109.

5 Cfr. Carmen Vázquez, "A Modo de Presentación”, in Carmen Vásquez (ed.), Estándares de Prueba y Prueba Científica, Marcial Pons, Madrid, 2013, p. 17. 
O juiz aprecia o rigor do método, a veracidade das suas premissas e a consistência das suas conclusões. O que se exige é que o juiz seja capaz de valorar se está perante uma forma de conhecimento dotada de dignidade e validade científica, e se os métodos de investigação e controlo típicos dessa ciência foram corretamente aplicados no caso concreto. Em suma, trata-se de confirmar se existem condições de cientificidade da prova. ${ }^{6}$

Se essas condições de cientificidade da prova ocorrerem, as máximas da experiência especializadas trazidas pelo perito deverão, em princípio, prevalecer sobre a prova testemunhal. Note-se que a testemunha não observa o facto da mesma forma que um observador com conhecimentos técnicos, ou seja, o leigo não é competente para observar corretamente o acontecimento de um ponto de vista científico. Em suma, se está em causa apurar um facto cuja solução depende de uma apreciação científica e se a prova pericial for produzida segundo os padrões científicos pertinentes e atendíveis, deverá prevalecer esta sobre a opinião de um leigo.

Na formulação desse juízo sobre a prevalência, ou não, do laudo pericial sobre a prova testemunhal, poderão ser determinantes os esclarecimentos verbais prestados pelos peritos no decurso da audiência, valorados com os fatores que a imediação põe em destaque, tais como: a segurança do perito ao revelar os seus resultados; as suas dúvidas, assumidas ou implícitas; a sua expressão, tom de voz. ${ }^{7}$

Há que atentar se as declarações do perito são coerentes, se o perito as contextualiza devidamente, se o perito apela e expressa os dados técnicos que corroboram os seus esclarecimentos (rigor científico e racionalidade). Os comentários oportunistas do perito, no sentido justificar a sua atuação e que excedem o âmbito do que lhe foi perguntado, deverão - em princípio - ser secundarizados porquanto, na maioria dos casos, são apenas defensivos da profissionalidade do seu trabalho. Todavia, quando o perito faz a comentários oportunistas de forma excessiva, tal poderá ser valorado como evidência de que o perito está consciente de que o seu trabalho não foi bem realizado e que, com essa atuação, o perito tenta disfarçar com retórica as deficiências da prestação. ${ }^{8}$

No processo penal, o Artigo $163^{\circ}, \mathrm{n}^{\circ} 1$, do CPP dispõe que o "O juízo técnico, científico ou artístico inerente à prova pericial presume-se subtraído à livre apreciação do julgador.” E, no n⿳2 do mesmo preceito, determina-se

6 Cf. Michele Taruffo, La Prueba, Marcial Pons, 2008, pp. 293-295.

7 Cf. Rosário Herrera Habián, La inmediación como garantía procesal (En el proceso civil y en el proceso penal), Editorial Comares, 2006, p. 56.

$8 \quad$ La Valoración de la Prueba, Marcial Pons, Madrid, 2010, pp. 308. 
que "Sempre que a convicção do julgador divergir do juízo contido no parecer dos peritos, deve aquele fundamentar a divergência."

Este regime decorre do ensinamento de Figueiredo Dias, segundo o qual «perante um certo juízo cientificamente provado, de acordo com as exigências legais, o tribunal guarda a sua inteira liberdade no que toca à apreciação da base de facto pressuposta; quanto porém ao juízo científico, a apreciação háde ser científica também e estará, por conseguinte, subtraída em princípio à competência do tribunal - salvo nos casos inequívocos de erro, mas nos quais o juiz terá então de motivar a sua divergência.» ${ }^{10}$

Resulta deste regime que o resultado da perícia não é livremente valorável pelo julgador, o qual deve fundamentar a sua divergência em relação às conclusões do perito. O julgador só pode arredar a conclusão inscrita no relatório pericial com fundamento numa crítica material da mesma natureza. Na explicação do Acórdão do Supremo Tribunal de Justiça de 11.2.2004, «Não vale uma crítica material procedente do julgador, alicerçada no seu critério pessoal, na forma particular de subjetivar os resultados, os factos, assente em conhecimentos meramente profanos, tudo sem apoio em conceitos científicos; se o julgador pudesse fundamentar a divergência sem apelo ao critério científico, seria uma forma, clara, de iludir, frustrar o comando imperativo resultante do $\mathrm{n}^{\circ} 2$, do art. $163^{\circ}$, do CPP, contraditória, até, nos seus termos, caindo-se na proibição a obstar, não se conciliando essa fundamentação própria e interpretação pessoal com a indispensabilidade do apoio científico.» ${ }^{11}$

9 A propósito da diversidade de regimes do processo civil e do processo penal sobre a valoração da prova pericial, discorreu o Tribunal Constitucional no seu Acórdão n 422/99 de 30.6.1999, Bravo Serra, www. tribunalconstitucional.pt., nestes termos:

"(...) no processo criminal, e porque não se pode olvidar que a inocência do arguido se presume até ao trânsito em julgado da sentença condenatória, sendo uma das suas garantias o próprio direito ao recurso quanto a sentenças impositoras de sanções penais, o dever de fundamentação da sentença quanto à matéria de facto háde impor-se com maior acuidade do que no domínio civil, sendo certo que desta afirmação não decorrerá desde logo que as soluções consagradas no processo penal são as únicas que se hãode considerar como conformes à Constituição ou, ao menos, como as mais conformes a ela.

Alcançado, assim, que, mesmo ponderando uma harmonia do sistema jurídico, daí não decorre que as leis adjetivas tenham de consagrar soluções idênticas, compreende-se que exista no processo criminal norma tal como a constante do $n^{\circ} 2$ do $\operatorname{art}^{\circ} 163^{\circ}$ do Código de Processo Penal, e que já não se surpreenda essa existência no Código de Processo Civil, exatamente porque nem sequer se estatui a presunção segundo a qual é subtraído à livre apreciação do juiz que o juízo técnico, científico ou artístico inerente à prova pericial. E, inexistindo essa presunção, torna-se claro que se não imporá, no domínio processual civil, uma prescrição semelhante à daquela norma."

10 Direito Processual Penal, Coimbra Editora, reimpressão de 1981, pp. 209-210.

11 Sendo relator Armindo Monteiro, CJ 2004-I, pp. 197-200. 
O julgador fundamenta suficientemente a sua divergência, nomeadamente quando adere: (i) às conclusões da opinião vencida numa perícia colegial; (ii) às "observações" expressas pelo consultor técnico (cf. Artigo $155^{\circ}$ do $\mathrm{CPP}$ ); (iii) a uma das opiniões perante duas ou mais perícias com resultados contraditórios. ${ }^{12}$

A prova pericial tem que ser apreciada pelo julgador a três níveis:

(i) Quanto à sua validade (respeitante à sua regularidade formal);

(ii) Quanto à base de facto pressuposta na perícia e

(iii) Quanto à própria conclusão da perícia.

No que tange ao primeiro nível, há que aferir se a prova foi produzida de acordo com a lei, se não foi produzida contra proibições legais e examinar se o procedimento da perícia está de acordo com normas da técnica ou da prática corrente.

Quanto à base de facto - cuja perceção e/ou apreciação não exija especiais conhecimentos - pressuposta na perícia, é lícito ao julgador divergir dela, sem que haja necessidade de fundamentação científica, porque não é posto em causa o juízo de carácter técnico-científico expendido pelos peritos, aos quais escapa o poder de fixação daquela matéria. ${ }^{13} \mathrm{Ou}$ seja, o Tribunal mantém a liberdade de apreciação da prova se a divergência se confinar aos factos em que se apoia o juízo pericial.

Quando é ordenada a realização de uma perícia e o resultado da mesma é inconclusivo, tal situação não conduz necessariamente a uma dúvida insanável. Como o resultado em causa não integra um verdadeiro juízo pericial mas antes um estado dubitativo, devolve-se plenamente ao tribunal a decisão sobre a matéria de facto de modo a superar, se possível, aquela dúvida. ${ }^{14}$ É o caso, por exemplo, dos exames periciais à letra e assinatura que, por vezes, são inconclusivos. Dito de outra forma, quando os peritos

12 Cf. Paulo Pinto de Albuquerque, Comentário ao Código de Processo Penal à Luz da Constituição da República Portuguesa e da Convenção Europeia dos Direitos do Homem, Universidade Católica Editora, $4^{\mathrm{a}}$ Ed., pp. 457-458. Como exemplo da situação referida em último lugar, veja-se o Acórdão do Tribunal da Relação de Coimbra de 10.5.2006, Orlando Gonçalves, CJ 2006 - III, pp. 43-47.

13 Cf. Acórdãos do Supremo Tribunal de Justiça de 9.5.1995, Costa Pereira, CJ 1995-II, pp. 189-190, de 25.10.1995, Amado Gomes, CJ 1995- III, pp. 211-212; Acórdão do Tribunal da Relação de Coimbra de 11.3.2009, Jorge Gonçalves, 4/05.

Estão sujeitos ao regime geral da livre apreciação da prova, a apreciação ou perceção de factos que, muito embora veiculados por um perito, não traduzam nenhum conhecimento especializado - Acórdão do Supremo Tribunal de Justiça de 19.10.2005, Sousa Fonte, CJ 2005-III, pp. 189-190.

14 Acórdãos do Supremo Tribunal de Justiça de 11.7.2007, Armindo Monteiro, 07P1416, de 1.10.2008, Raul Borges, 08P2035, Acórdão do Tribunal da Relação do Porto de 27.1.2010, Jorge Gonçalves, 45/06. 
não conseguiram lograr um parecer livre de dúvidas, quando se conclui por um juízo de mera probabilidade ou opinativo ${ }^{15}$, incumbe ao tribunal tomar posição, julgando segundo o princípio da livre apreciação da prova, não estando o Tribunal vinculado a um resultado que não assume natureza científica.

Também o juízo sobre a intenção de matar não integra um juízo técnico, científico ou artístico e nem é tão pouco um juízo de técnica médica; pelo contrário, a presunção de intenção de matar é apenas um juízo de probabilidade sobre aquela intenção, pelo que o mesmo não fica sujeito ao valor probatório reforçado preconizado no Artigo $163^{\circ}, \mathrm{n}^{\mathrm{o}} 1 .^{16}$

Se uma perícia médico-legal for realizada nos termos do Artigo $159^{\circ}$ do CPP e Lei $n^{\circ} 45 / 2004$, de 19.8. (pelo Instituto Nacional de Medicina Legal), a mesma beneficia do valor probatório imposto pelo Artigo $163^{\circ}, \mathrm{n}^{\circ} 1$ do CPP. Neste caso e demais similares, nada impede que a testemunha, durante o seu depoimento, se refira ao teor do exame pericial constante dos autos. O que está vedado à testemunha é pronunciar-se sobre o juízo técnico/ científico constante da perícia. ${ }^{17}$

Diversamente, os relatórios de avaliação psicológica com estudo de personalidade e de avaliação psiquiátrica elaborados por psicólogo clínico e por um médico psiquiatra (apresentados pelo arguido no decurso da audiência de julgamento e cujos subscritores deponham como testemunhas), porque não realizados nos termos das disposições citadas (Artigo $159^{\circ}$ do CPP e Lei $n^{\circ} 45 / 2004$, de 19.8.), não estão submetidos à regra da prova vinculada do Artigo 163. ${ }^{\circ}$, n. $^{\circ}$ 1, estando sujeitos à livre apreciação do tribunal nos termos do Artigo $127^{\circ}$ do $\mathrm{CPP}{ }^{18}$ De forma equivalente, não pode ser

15 Se o juízo de imputabilidade diminuída, formulado pelo perito, foi emitido como uma probabilidade, e não como um juízo técnico-científico é legítimo ao tribunal, com base em investigação definitiva dos factos, apreciados livremente, nos termos do artigo $127^{\circ}$ do CPP, concluir pela existência de uma total inimputabilidade - Acórdão do Supremo Tribunal de Justiça de 20.10.1999, Armando Leandro, CJ 1999- III, pp. 196-197.

16 Cf. Acórdão do Supremo Tribunal de Justiça de 3.7.96, Flores Ribeiro, CJ 1996-II. Pp. 214-215.

17 Cf. Acórdão do Tribunal da Relação de Lisboa de 15.9.2011, Carlos Benido, 1154/07, www.colectaneadejurisprudencia.com.

18 Acórdão do Supremo Tribunal de Justiça de 19.3.2009, Fernando Fróis, 09P0392. A propósito da articulação do relatório pericial ordenado no processo com os conhecimentos profissionais de testemunhas que são médicos, no Acórdão do Tribunal da Relação de Évora de 5.2.2013, Gomes de Sousa, 529/08, raciocinou-se assim:

"É certo que se suscita, com os médicos inquiridos como testemunhas e que emitem um "juízo" médico sobre a matéria dos autos, um problema de cariz processual que outras legislações resolvem através da criação de uma figura híbrida de "testemunha" e "perito", o "temoin-expert".

Confusão que também ocorre quando se pretenda fazer - erradamente - a analogia com os sistemas anglo-saxónicos, que em regra apelidam o "perito" como "expert-witness", o que se compreende pela 
atribuído o valor de prova pericial a depoimento de alguém com formação técnico-científica, v.g., testemunha psicóloga, que, pelas suas declarações, confere "credibilidade" às declarações de menor vítima de crime de abuso sexual, mesmo que tal psicóloga tenha prestado assistência e acompanhado a vítima. Tratar-se-á de um depoimento eventualmente qualificado mas que não assume o caráter de prova pericial produzida nos termos legais. ${ }^{19}$

generalizada inexistência - por ora - de peritagem oficial ou, ao menos, pela generalizada e sistemática aceitação de opiniões periciais de testemunhas que o tribunal aceite com a qualidade de "expert-witness" e no exercício de um contraditório amplo e privatístico no âmbito específico da perícia.

0 sistema processual penal português não consagra tal figura híbrida, ou um sistema de perícias contraditórias, acolhendo um sistema oficial de peritagens, designadamente as de cariz médico-forense. Mas não proíbe a testemunha de "emitir opinião" sobre matéria técnica ou científica que esteja no âmbito dos seus conhecimentos, desde que assente num conhecimento perfeito e não parcial dos factos. 0 peso relativo a atribuir a tais "opiniões", aqui no sentido positivo de opinião sustentada numa correta perceção dos factos aceites pelo tribunal como provados, racionalmente fundada, de acordo com os princípios técnicos ou científicos a atender e passível de revisão face a "provas contrárias ou raciocínios mais bem fundamentados", está necessariamente, por imposição legal, inserido no princípio da livre apreciação probatória e dependente - na sua aceitação substancial - da devida fundamentação do tribunal recorrido.

Como já afirmou o relator, é «dever do tribunal, como do filósofo, "defender o raciocínio dialógico entre as opiniões, a necessidade de justificar o opinado não a partir do inefável, do irredutível ou do inverificável, mas sim através do publicamente acessivel, do inteligível"» (Fernando Savater).

E, para esse desiderato, ouvir várias opiniões válidas e consistentes racional e científicamente, apresenta uma coloração positiva.

Mas enfrenta um obstáculo inultrapassável - com consagração legal - a prevalência formal e substancial da opinião do perito, que apenas pode ser afastada pelo tribunal nos termos do disposto no artigo $163^{\circ}$ do Código de Processo Penal, no que muitos consideram uma limitação ao princípio da livre apreciação e que nós vemos como uma regra qualificada da livre apreciação probatória (v. g. 0 $\mathrm{n}^{\circ} 2$ do artigo $163^{\circ}$ do Código de Processo Penal).

Ou seja, a opinião emitida por um médico que seja testemunha no processo que incida sobre matéria médica objeto do processo, não obstante qualificada pelo seu conhecimento profissional, será sempre uma opinião não qualificada, face à opinião pericial.

Daqui resulta que, havendo discrepância entre a opinião pericial e a opinião de um qualquer médico que seja testemunha, prevalecerá sempre a opinião pericial, a não ser que o tribunal fundamente, com a razão e os conhecimentos técnicos e científicos implicados no caso, a divergência da opinião pericial, se assumir como sua a "opinião" não (processualmente) qualificada de uma testemunha ou se optar por uma visão científica ou técnica própria.

Isto é, o artigo $163^{\circ}, \mathrm{n}^{\circ} 2$ do Código de Processo Penal é aplicável não só à convicção livre e racional do juiz enquanto processo interior mas racional de convicção e posterior motivação, também à apreciação probatória feita pelo tribunal relativamente a vários e diferentes meios probatórios, com uma obrigação legal e científica de fundamentar devidamente a não-aceitação da opinião pericial e o dar prevalência à "opinião" divergente constante de qualquer outro meio de prova."

19 Cf. Artigo $131^{\circ}, \mathrm{n}^{0} 3$, do CPP, que prevê a realização de perícia sobre a personalidade de menor de 18 anos vítima de crime sexual. No sentido aludido, cf. Maria do Carmo Silva Dias, "Particularidades da Prova em Processo Penal. Algumas Questões Ligadas à Prova Pericial", in Revista do CEJ, N 2, $2^{\circ}$ Semestre 2005, p. 221. 
O regime consagrado no Artigo $163^{\circ}$ do CPP evidencia a entronização da prova pericial, à qual vem sendo atribuída uma certa áurea de infabilidade e de superioridade face à prova não científica. Assim, afirma-se que a prova científica se articula mediante um raciocínio dedutivo enquanto a prova não científica se estrutura mediante um raciocínio indutivo. Todavia, as provas científicas não constituem em geral um raciocínio do tipo dedutivo, assentando prevalentemente em leis estatísticas e os seus resultados devem ser interpretados à luz de outros dados, o que impede que este tipo de conhecimento se arrogue como puramente objetivo.

Gascón Abellán afirma que prova científica tem sido objeto de uma sobrevalorização epistémica na medida em que os seus resultados são tidos como infalíveis, bem como se uma sobrevalorização semântica na medida em que se considera que os resultados da prova científica dizem coisas distintas do que, na realidade, dizem. ${ }^{20}$

Assim, a qualidade epistémica dos resultados da prova científica depende de vários fatores, designadamente:

(i) Da validez científica e/ou metodológica da prova científica porquanto nem todos os métodos científicos gozam do mesmo crédito na comunidade científica;

(ii) Da sua qualidade técnica, designadamente da correção técnico-procedimental que vai desde o descobrimento do vestígio, sua custódia, até à análise em laboratório;

(iii) Da correção técnico-científica na parte atinente à realização da perícia em laboratório por pessoal qualificado e com observância dos protocolos adequados;

(iv) Dos riscos cognitivos de algumas provas como a dactiloscópica que têm uma forte componente comparativa, ficando sob a supervisão do perito. Deste modo, a fiabilidade dos resultados da prova científica não deve ser dada por adquirida.

No que tange à sobrevalorização semântica da prova científica, o paradigma que tem vigorado nas ciências forenses é o paradigma da individualização, segundo o qual existe a capacidade de identificar plenamente um indivíduo ou um objeto a partir de vestígios.

Contudo, este paradigma tem sido ultimamente objeto de críticas por parte da comunidade científica, argumentando-se que a pretensão de vincular

20 "Prueba Científica. Un Mapa de Retos", in Carmen Vásquez (ed.), Estándares de Prueba y Prueba Científica, Marcial Pons, Madrid, 2013, pp. 181-187. 
um vestígio desconhecido a uma única fonte representa uma equivocada intuição probabilística que iguala infrequência com unicidade, ou seja, considera-se impossível obter prova concludente da unicidade. Os críticos do paradigma da individualização propugnam que os resultados da prova científica têm que ser interpretados, não em termos de identificação de um vestígio com uma fonte, mas em termos de razão de verosimilitude ("likelihood ratio"). ${ }^{21}$ Assim, o resultado de uma análise de voz ou uma comparação de perfis de ADN a partir de um vestígio não diz - de forma conclusiva nem provavelmente - que a voz e o ADN analisados pertencem à pessoa $y$ mas, simplesmente, contribuem com dados que, uma vez interpretados com as adequadas ferramentas estatísticas, afirmam coisas do género: "é x vezes mais provável que se observe tal caraterística na voz analisada se este pertencer ao arguido do que se não pertencer" ou "é x vezes mais provável que coincidam os perfis genéticos se o vestígio analisado proceder do arguido do que se proceder de uma fonte distinta.". Em suma, "as provas científicas tratam da probabilidade de os dados analíticos e técnicos, resultantes depois da análise no laboratório, à luz das hipóteses judiciais examinadas, e não ao contrário: isto é, não tratam da probabilidade das hipóteses judiciais consideradas à luz desses dados.”22 Em coerência com esta posição, deve abandonar-se a metodologia corrente de expressar os resultados da prova científica em termos de identificação categórica, v.g., "provável", "muito provável”. Estas escalas reproduzem o paradigma da identificação, estabelecendo, não o que dizem os dados, mas o que deve crer-se sobre a hipótese em apreciação a partir dos dados.

O paradigma da verosimilitude propõe valorar os resultados das provas científicas, formulando três questões:

(i) O que dizem os dados e observações resultantes da prova científica sobre a hipótese A em relação com a hipótese B;

(ii) $\mathrm{O}$ que devemos crer a partir desses dados e

(iii) $\mathrm{O}$ que devemos fazer.

21 Em termos estatísticos, "likelihood" não é equivalente a probabilidade ("probability"). A primeira designação reporta-se à possibilidade de os dados ocorrerem, no caso de uma hipótese ser verdadeira, enquanto a segunda se refere à possiblidade de que a hipótese seja verdadeira, atentos os dados observados - cfr. Kevin Clermont, "Standards of Proof Revisited", http://scholarship.law.cornell.edu/ facpub/13/, p. 479, Nota 19.

22 Gascón Abellán, "Prueba Científica. Un Mapa de Retos", in Carmen Vásquez (ed.), Estándares de Prueba y Prueba Científica, Marcial Pons, Madrid, 2013, p. 187. 
A resposta à primeira questão é a principal tarefa do perito, o qual deve interpretar e comunicar o resultado da perícia feita em laboratório, expressando-a nos termos já enunciados.

A resposta à segunda questão integra a avaliação da veracidade das hipóteses em confronto, a qual tem de assentar no que dizem os dados científicos mas também no que resulta das restantes provas produzidas. Esta tarefa incumbe ao juiz que pauta a sua decisão pelo conjunto da prova produzida e norteado pelo princípio da livre apreciação da prova. Ou seja, o juiz é que determina o que há que crer sobre a hipótese em apreciação à luz da prova pericial e também do resto das provas disponíveis no processo. Neste preciso sentido, o juiz valora a prova e não é propriamente o perito dos peritos. Aqui reside a diferença essencial entre o paradigma da individualização e da verosimilitude porquanto naquele não se distingue claramente entre a tarefa do perito e a do juiz.

No que tange à terceira questão (o que devemos fazer), a mesma remete para o standard da prova aplicável ao caso em apreço. Isto é, partindo-se do que se deve crer, há que aquilatar se tal é suficiente para que possamos considerar provada uma hipótese e atuar em conformidade.

A fixação de um standard de prova é uma questão política e valorativa no sentido de que expressa a tolerância que o sistema está disposto a dar aos erros que podem ocorrer com a prolação da decisão, quais sejam: o de se declarar provado algo que é falso ou de se declarar não provado o que é verdadeiro. No processo civil, o standard da prova é, em regra, o da "preponderance of evidence"("more-likely-than-not") e no processo penal é o da "evidence beyond a reasonable doubt". ${ }^{23}$

23 Sobre o standard de prova, cf., desenvolvidamente, o nosso Prova por Presunção no Processo Civil, Almedina, 2013, $2^{\text {a }}$ ed., pp. 149-157. 